\title{
DO HEXÂMETRO AO DECASSÍLABO - EQUIVALÊNCIA ESTILÍSTICA BASEADA NA MATERIALIDADE DA EXPRESSÃO
}

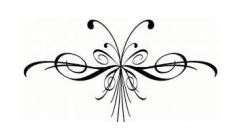

MÁrcio THAMOS ${ }^{1}$

\begin{abstract}
Resumo: A expressividade que uma língua alcança através da poesia está relacionada com a natural adequação da fala a um determinado ritmo prosódico. O decassílabo não é uma mera convenção métrica; ele constitui-se numa espécie de frase ideal do português, um modelo de fala ludicamente construído através da percepção viva da língua para permitir a expressão justa do significado poético. O mesmo pode-se dizer do hexâmetro com relação ao latim. A tradição literária do português atesta certa equivalência estilística entre o decassílabo e o hexâmetro. Assim, parece lícito buscar balizas para a tradução que permitam ratificar empiricamente essa equivalência, a fím de, a partir daí, deduzir-se um modelo flexível de proporcionalidade métrica fundada na materialidade da expressão.
\end{abstract}

Palavras-chave: Métrica, ritmo, hexâmetro, decassílabo, Ovídio, Bocage

\begin{abstract}
This paper deals with the relationship between the Latin hexametre and the Portuguese decasyllable, mainly paying attention to the possibility of a translation which could save some stylistic equivalence based on the proportionality of the materiality of expression.
\end{abstract}

Keywords: Metrics, rhythm, hexametre, decasyllable, Ovid, Bocage

$\mathrm{E}$ ntre os linguistas, há o entendimento pacífico de que "nos processos de transcodificação, traduzem-se as substâncias do conteúdo através de equivalências postuladas entre códigos formais" (LOPES: 2005, p. 95). "Transcodificar" a substância do conteúdo é, portanto, pressuposto básico de qualquer tradução. Mas, quando se trata de

\footnotetext{
${ }^{1}$ Professor da Área de Latim (Departamento de Linguística) - Faculdade de Ciências e Letras, UNESP, Câmpus de Araraquara/SP - e coordenador do Grupo LINCEU: Visões da Antiguidade Clássica/CNPq.
} 
traduzir poemas, manter-se apenas essa preocupação básica com a substância do conteúdo não resulta, na língua de chegada, em um texto que possa ser qualificado como poesia. Traduzir-se apenas a substância do conteúdo de um poema resultará em um texto de prosa, eventualmente prosaico, despojando-se assim a poesia de suas qualidades expressivas mais específicas, quais sejam, os elementos responsáveis pela, por assim dizer, "poeticidade" do texto original.

É de se imaginar que a tradução de um texto poético só passa a ter um caráter de poesia quando, juntamente com a preocupação básica de traduzir a substância do conteúdo, intenta-se também uma tradução da substância da expressão, aspecto fundamental do discurso poético com frequência negligenciado em traduções. Restringindo-se a questão mais especificamente aos textos versificados, impõe-se a necessidade de se pensar no metro como o primeiro elemento discursivo responsável pela expressividade da poesia.

Para Joseph Brodsky (1994, p. 84), "a tradução é a procura de um equivalente, e não de um substituto. Requer pelo menos uma afinidade estilística, quando não psicológica". Levando-se em conta a definição sinteticamente assim formulada pelo poeta e ensaísta russo, a busca de uma equivalência métrica fundada na materialidade da expressão poderia constituirse numa espécie de diretriz geral que regulasse a tradução no que diz respeito, ao menos, às bases daquela afinidade estilística que se reclama.

O metro é um amplo princípio ordenativo que se verifica na composição dos textos poéticos. Mas trata-se de uma noção que comumente gera certas dificuldades teóricas. É, por isso, interessante deter-se um pouco no assunto, a fim de procurar esclarecer em que termos se entende aqui o metro.

No ensaio "Linguística e poética", Roman Jakobson (2001, p. 139-140) diz:

Longe de ser um esquema abstrato, teórico, o metro - ou, em termos mais explícitos, o modelo de verso (verse design) - domina a estrutura de qualquer verso particular - ou, em terminologia lógica, todo exemplo de verso (verse instance). Modelo e exemplo são conceitos correlativos. O modelo de verso determina as características invariáveis dos exemplos de verso e estabelece o limite de variações.

Essas variações são, naturalmente, engendradas pelo ritmo próprio de cada verso. $\mathrm{O}$ metro seria assim uma espécie de estrutura rítmica de base para o poema.

Octavio Paz escreveu uma extensa nota de rodapé para a terceira edição de El arco y la lira (cf. 1990, p. 71) justamente para contestar o que diz Jakobson na citação acima. Para o ensaísta mexicano (1990, p. 70),

La única exigencia del metro es que cada verso tenga las sílabas y acentos requeridos. Todo se puede decir en endecasílabos: una fórmula matemática, una receta de cocina, el sitio de Troya y una sucesión de palabras inconexas. Incluso se puede prescindir de la palabra: basta con una hilera de sílabas o de letras. En sí mismo, el metro es medida desnuda de sentido.

Esse argumento que, em princípio, desqualifica o metro, lembra palavras de ordem das vanguardas do início do século XX em favor do verso livre. Observar que mesmo uma receita de cozinha pode ser escrita respeitandose um determinado número fixo de sílabas por linha parece particularmente 
persuasivo quanto à total impertinência do metro. Mas é constrangedor admitir tamanha ingenuidade nos poetas que, desde sempre, se obrigassem a manter regras de composição tão difíceis quanto vãs. Se, nessa questão, se concorda com o ensaísta mexicano, não há como deixar de reconhecer uma delirante insensatez em Homero, Virgílio, Dante, Camões, Shakespeare ou, contemporaneamente, Derek Walcott, por exemplo.

Voltando ao argumento de Octavio Paz, é preciso notar também o óbvio: se o fato de se poder dizer uma receita "en endecasilabos" prova que o metro é uma exigência sem sentido, nenhuma alternativa resta à poesia. Com efeito, não se pode igualmente escrever uma receita em prosa ou em versos livres? Por outro lado, não é incomum a revisitação do metro fixo pelos próprios poetas que o combateram. Em outras palavras, é preciso desconfiar desse julgamento que aparece em El arco y la lira. O ensaísta mexicano opõe o metro - como medida destituída de qualquer sentido - ao ritmo - como elemento pleno de sentido -, que em si só "constituye, real o potencialmente, una frase poética completa" (1990, p. 70). Mas essa oposição tão radical provoca um grande equívoco. Primeiro deve-se notar o exagero da afirmação: o sentido completo de qualquer frase só se constrói pela concorrência de vários elementos linguísticos. Depois é preciso reconhecer que, se o ritmo chega a ganhar certo sentido, isso se dá, na verdade, pelo emprego do metro. Na música, por exemplo, o silêncio só se torna significativo, isto é, adquire um valor como figura rítmica, por estrita adequação à métrica ${ }^{2}$.

A noção de ritmo, por ser extremamente ampla, só comporta um sentido muito genérico. Basta notar que ela se verifica em tudo o que concerne à vida e não é estranha ao próprio caos primordial. No que se refere à linguagem, ritmo é um fato natural de fala, de qualquer fala. Num artigo de jornal ou num tratado científico, a sequência de tônicas e átonas, na cadência natural da leitura, necessariamente instaura algum ritmo. Mas à poesia não convém um ritmo qualquer. O metro é o instrumento através do qual o poeta, de acordo com suas necessidades expressivas, organiza o ritmo natural da fala, modelando-o significativamente em seus versos. Daí Roman Jakobson ter razão quando enfatiza que o metro não é uma simples abstração, contrariando o pensamento de Octavio Paz.

A precipitação do ilustre ensaísta mexicano, nesse caso, é motivada, possivelmente, pela identificação - e consequente repúdio - da noção de metro com a tradicional descrição que dela se fez. Os tratados de métrica, em geral, mostram o verso como uma espécie de leito de Procusto destinado às palavras. Nada, nas regras que se apresentam, parece justificável do ponto de vista da necessidade expressiva. Tudo que se espera é que as palavras se encaixem com perfeição, numa rigorosa disciplina a serviço apenas de si mesma. Mas, naturalmente, não é essa a métrica dos poetas. O metro - é evidente - tem uma função expressiva em poesia, e é isso o que justifica sua existência.

Os Cantos populares do Brasil, coligidos no final do século XIX por Sílvio Romero (1985), são prova clara de que o metro não é uma imposição pedante da cultura poética, mas uma disposição própria da poesia que, como manifestação temporal, por natureza, se aproxima da música. Antes de mais nada, o metro está ligado a um desejo de "ordenar o mundo", conforme "a

\footnotetext{
${ }^{2}$ Pois, ainda que de caráter experimentalista ou improvisatório, qualquer manifestação musical não pode prescindir de uma estrutura formal.
} 
imperecível necessidade humana de viver em beleza" (1996, p. 71), de que fala Johan Huizinga. Sem dúvida, deve-se concordar que o metro por si não garante a poesia. Mas ele cria as condições rítmicas necessárias ao texto poético, ao impor limites às variações possíveis. Isso, que pode parecer a princípio um obstáculo à composição do poema, revela-se, na verdade, um elemento estrutural que favorece o desenvolvimento do texto uma vez que restringe muito a indeterminação melódica dos versos, ao fornecer-lhes balizas de referência ${ }^{3}$.

Note-se também que as palavras recebem, através da métrica, um arranjo ordenativo que reforça extraordinariamente sua unidade como texto. Esse arranjo procura garantir que elas sigam-se umas às outras de maneira mais orgânica e necessária. Assim, vale dizer, o metro é o aboio do poeta tangendo palavras. É bastante significativo que o repentista - que a princípio dispensa tudo, qualquer preparo que preestabeleça bases para sua performance enunciativa - só não dispense o metro. É esse o patamar mais profundo de sustentação de sua expressão. Até o último instante que precede a emissão de voz, a fala do cantador só está protegida contra o caos discursivo pela disposição métrica com que ele se arma para o embate verbal ${ }^{4}$.

É só por experimentalismo, e quando a poesia está quase inteiramente confinada à expressão escrita, que o verso livre pode-se afirmar. Contudo, poema em versos livres não significa poema sem métrica. De um modo geral, o verso livre veio secundar o papel fundamental do metro como princípio de ordem e regularidade baseado na repetição. A partir de sua generalização, tornase patente que a métrica é importante pela criação de um padrão rítmico em torno do qual os versos se mantenham, isto é, pelo estabelecimento de um modelo relativo - e não absoluto - para a versificação do texto. É, aliás, o que atesta com tranquilidade o próprio modernista Manuel Bandeira ([19--], p. 115) quando, em busca de uma definição, conclui que

O verso é a unidade rítmica do poema. Ritmo, em sua fórmula elementar, é repetição. $\mathrm{O}$ verso, em sua essência, é unidade rítmica porque se repete e forma séries. Para formar séries podem as unidades ser semelhantes ou dessemelhantes.

Johan Huizinga (1996, p. 142) faz notar que

\footnotetext{
${ }^{3}$ Nesse sentido, é interessante lembrar o depoimento de Paul Valéry (1999, p. 210), falando sobre "Poesia e pensamento abstrato": "Meu poema O Cemitério Marinho começou em mim através de um certo ritmo, que é o do verso francês de dez sílabas, cortado em quatro e seis. Ainda não tinha a menor ideia para preencher essa forma. Aos poucos fixaram-se palavras flutuantes determinando gradativamente o tema, e o trabalho (um longuíssimo trabalho) impôsse. Um outro poema, A Pítia, ofereceu-se primeiramente através de um verso de oito sílabas, cuja sonoridade se compôs por si mesma. Mas esse verso supunha uma frase da qual ele era uma parte, e essa frase supunha, se tinha existido, muitas outras frases. Um problema desse tipo admite uma infinidade de soluções. Mas em poesia as condições métricas e musicais restringem muito a indeterminação. Eis o que aconteceu: meu fragmento se comportou como um fragmento vivo, pois, submerso no meio (sem dúvida nutritivo) que lhe era oferecido pelo desejo e pela espera de meu pensamento, ele proliferou e gerou tudo o que lhe faltava: alguns versos acima dele e muitos versos abaixo".

${ }^{4}$ É importante observar que mesmo a rima, tão cara à poética da modernidade, por sua própria natureza, isto é, sendo um elemento rítmico do poema, permanece na dependência do metro.
} 
Toda civilização só muito lentamente vai abandonando a forma poética como principal método de expressão das coisas importantes para a vida da comunidade social. A poesia sempre antecede a prosa; para a expressão de coisas solenes ou sagradas, a poesia é o único veículo adequado.

Essa observação pode ser confirmada por vários exemplos da história literária. No que diz respeito às literaturas latina e portuguesa, $A$ Eneida e $O s$ Lusíadas representam respectivamente modelos acabados do emprego da poesia na expressão dos valores mais sublimes de uma sociedade. Ressalte-se aqui o fato de Virgílio ter adotado o hexâmetro datílico como modelo métrico de sua obra, e lembre-se que Camões, por sua vez, elegeu o decassílabo como padrão de composição da sua. Nos dois casos, a escolha do metro parece corroborar estilisticamente a grandeza do tema cantado.

A expressividade que uma língua alcança através da poesia está relacionada com a natural adequação da fala a um determinado ritmo prosódico. O decassílabo não é uma mera convenção métrica; ele constitui-se numa espécie de frase ideal do português, um modelo de fala ludicamente construído através da percepção viva da língua para permitir a expressão justa do significado poético. Apesar da impossibilidade histórica de se conhecer de fato a prosódia da língua dos antigos romanos, o mesmo valor se pode atribuir ao hexâmetro com relação ao latim.

O verso latino é formado por uma sequência de sílabas longas, indicadas pelo macro $\left(^{-}\right.$) e breves, indicadas pela braquia $\left(^{-}\right)$. Uma longa equivale metricamente a duas breves. Agrupadas em unidades rítmicas, as sílabas compõem os pés métricos. O hexâmetro datílico é um verso composto por seis pés de quatro tempos cada (uma sílaba breve corresponde a um tempo, e uma longa a dois). Os quatro primeiros pés são dátilos ou espondeus, isto é, unidades compostas pela sequência de uma sílaba longa e duas breves $\left(^{-}{ }^{-}\right.$) ou de duas sílabas longas (- - $^{-}$. O quinto pé, que caracteriza o verso, é necessariamente um dátilo ( $\left.{ }^{-}{ }^{-}\right)$, e o último, um espondeu $\left(^{-{ }^{-}}\right.$) ou um troqueu $\left({ }^{-}\right)^{5}$. Completa esse esquema métrico a cesura ( $\|$ ), uma espécie de corte semântico que estabelece o equilíbrio rítmico-sintático do verso, fixada normalmente após a primeira sílaba do terceiro ou do quarto pé (embora possam ocorrer cesuras em outros pontos do hexâmetro). A título de exemplo, veja-se a escansão de um verso de Ovídio, extraído do livro das Metamorfoses (XV, 253):

\section{EEx ălì|īs ăli||ās || rēd|dìt nā|tūră fî|gūrās} [Ex aliis alias reddit natura figuras $\left.{ }^{6}\right]$.

Na melhor tradição literária do português, o decassílabo é um verso de dez sílabas poéticas que recebe um acento prosódico regular na sexta. A este costuma-se chamar heroico. Quando ocasionalmente o acento não ocorre na sexta sílaba, exigem-se acentos na quarta e na oitava. Essa variação tradicional do decassílabo recebe quase sempre a denominação de sáfico. Nota-se assim a preocupação métrica de garantir o equilíbrio rítmico ideal da unidade frasal do poema: o acento regular do heroico corta o verso ao meio, organizando-o em

\footnotetext{
${ }^{5}$ A última sílaba do verso tem, na verdade, sua duração neutralizada pela pausa final, daí a possibilidade de ser longa, no caso do espondeu, ou breve, no caso do troqueu, sem que isso represente variação formal do modelo rítmico de vinte e quatro tempos.

6 "A Natureza cria figuras diferentes a partir de diferentes figuras".
} 
duas porções foneticamente proporcionais e, quando isso não ocorre, a distribuição acentual do sáfico procura manter o equilíbrio rítmico reorganizando o decassílabo em três porções fônicas equivalentes. Como exemplo, notem-se os seguintes versos de Bocage, extraídos de sua tradução para o episódio d'“O roubo de Europa por Júpiter" (Metamorfoses, II), que descrevem a forma assumida pelo pai dos deuses a fim de lograr seu intento:

Veste forma taurina entre as manadas

Muge, e pisa formoso as brandas ervas

É cor da neve, que nem pés calcaram

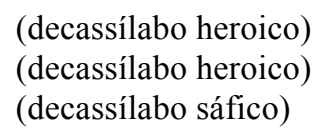

O hexâmetro datílico apresenta uma constituição que varia de 13 a 17 sílabas, de acordo com o arranjo de longas e breves que formam os pés, em cada verso. Pode-se assim imaginar a média ideal de 15 sílabas no verso latino. $\mathrm{O}$ decassílabo português por sua vez terá, em termos absolutos, uma média ideal de 11 sílabas, e não exatamente de 10 como se pode ser levado a pensar de início. Isso se deve à observação de que a regra vernácula mais geral determina um acento prosódico na penúltima sílaba das palavras, que assim são denominadas paroxítonas. Desse modo, dividindo-se 15 por 11 , a paridade métrica na tradução de hexâmetros em decassílabos baseada numa proporcionalidade silábica absoluta entre os versos pode ser expressa pela relação matemática de 1,3666... decassílabos por hexâmetros. Arredondando-se o resultado para 1,40, a fim de absorver a dízima periódica numa única casa decimal, chega-se a uma proporção ideal, em números inteiros, de 7 decassílabos para 5 hexâmetros.

Ao traduzir trechos selecionados das Metamorfoses de Ovídio (43 a. C.-17 d. C.), obra inteiramente composta em hexâmetros datílicos, o célebre poeta português Bocage (1765-1805) empregou apenas o decassílabo camoniano, o que denota a busca de uma equivalência estilística apoiada na escolha do metro ${ }^{7}$. Bocage verteu aproximadamente 1969 hexâmetros em 2852 decassílabos. A partir da análise estatística dos episódios traduzidos, pode-se constatar empiricamente a justa medida de uma relação entre decassílabos e hexâmetros que gire em torno da proporção de 1,40 (2852 dec. : 1969 hex. = $1,44 \mathrm{dec}$./hex.).

Tome-se como amostra o seguinte episódio das Metamorfoses (X, 1$82)^{8}$, em que se narra a descida de Orfeu ao reino de Plutão:

Inde per inmensum croceo velatus amictu

Aethera digreditur Ciconumque Hymenaeus ad oras

Tendit et Orphea nequiquam uoce uocatur.

Adfuit ille quidem, sed nec sollemnia uerba

5 Nec laetos uoltus nec felix attulit omen.

Fax quoque, quam tenuit, lacrimoso stridula fumo

Vsque fuit nullosque inuenit motibus ignes.

Exitus auspicio grauior ; nam nupta per herbas

Dum noua naiadum turba comitata uagatur,

10 Occidit in talum serpentis dente recepto.

Quam satis ad superas postquam Rhodopeius auras

\footnotetext{
${ }^{7}$ Para as traduções de Bocage, confira a atual edição organizada por João Angelo Oliva Neto (OVÍDIO, 2007).

${ }^{8}$ Segundo o texto das edições Les Belles Lettres, vol. 2 (cf. "Ref. bibliográficas”).
} 
Defleuit uates, ne non temptaret et umbras,

Ad Styga Taenaria est ausus descendere porta ;

Perque leues populos simulacraque functa sepulcro

15 Persephonen adiit inamoenaque regna tenentem

Vmbrarum dominum pulsisque ad carmina neruis

Sic ait: «O positi sub terra numina mundi,

In quem reccidimus, quicquid mortale creamur ;

Si licet et falsi positis ambagibus oris

20 Vera loqui sinitis, non huc, ut opaca uiderem

Tartara, descendi, nec uti uillosa colubris

Terna Medusaei uincirem guttura monstri ;

Causa uiae coniunx, in quam calcata uenenum

Vipera diffudit crescentesque abstulit annos.

25 Posse pati uolui nec me temptasse negabo ;

Vicit Amor. Supera deus hic bene notus in ora est ;

An sit et hic, dubito ; sed et hic tamen auguror esse ;

Famaque si ueteris non est mentita rapinae,

Vos quoque iunxit Amor. Per ego haec loca plena timoris,

30 Per Chaos hoc ingens uastique silentia regni,

Eurydices, oro, properata retexite fata.

Omnia debentur uobis, paulumque morati

Serius aut citius sedem properamus ad unam.

Tendimus huc omnes, haec est domus ultima uosque

35 Humani generis longissima regna tenetis.

Haec quoque, cum iustos matura peregerit annos,

Iuris erit uestri ; pro munere poscimus usum.

Quod si fata negant ueniam pro coniuge, certum est

Nolle redire mihi ; leto gaudete duorum. »

40 Talia dicentem neruosque ad uerba mouentem

Exsangues flebant animae; nec Tantalus undam

Captauit refugam stupuitque Ixionis orbis,

Nec carpsere iecur uolucres urnisque uacarunt

Belides inque tuo sedisti, Sisyphe, saxo.

45 Tunc primum lacrimis uictarum carmine fama est

Eumenidum maduisse genas; nec regia coniunx

Sustinet oranti, nec qui regit ima, negare

Eurydicenque uocant ; umbras erat illa recentes

Inter et incessit passu de uulnere tardo.

50 Hanc simul et legem Rhodopeius accipit Orpheus, Ne flectat retro sua lumina, donec Auernas

Exierit ualles; aut irrita dona futura.

Carpitur accliuis per muta silentia trames,

Arduus, obscurus, caligine densus opaca.

55 Nec procul afuerunt telluris margine summae;

Hic, ne deficeret metuens auidusque uidendi,

Flexit amans oculos et protinus illa relapsa est ;

Bracchiaque intendens prendique et prendere certans,

Nil nisi cedentis infelix arripit auras.

60 Iamque iterum moriens non est de coniuge quicquam

Questa suo (quid enim nisi se quereretur amatam?)

Supremumque « uale », quod iam uix auribus ille

Acciperet, dixit, reuolutaque rursus eodem est.

Non aliter stupuit gemina nece coniugis Orpheus

65 Quam tria qui timidus, medio portante catenas,

Colla canis uidit, quem non pauor ante reliquit

Quam natura prior, saxo per corpus oborto ;

Quique in se crimen traxit uoluitque uideri

Olenos esse nocens, tuque, o confisa figurae,

70 Infelix Lethaea, tuae, iunctissima quondam 
Pectora, nunc lapides, quos umida sustinet Ide.

Orantem frustraque iterum transire uolentem

Portitor arcuerat; septem tamen ille diebus

Squalidus in ripa Cereris sine munere sedit ;

75 Cura dolorque animi lacrimaeque alimenta fuere.

Esse deos Erebi crudeles questus, in altam

Se recipit Rhodopen pulsumque aquilonibus Haemum.

Tertius aequoreis inclusum Piscibus annum

Finierat Titan omnemque refugerat Orpheus

80 Femineam Venerem, seu quod male cesserat illi, Siue fidem dederat; multas tamen ardor habebat Iungere se uati; multae doluere repulsae.

\section{Tradução de Bocage?}

De rutilantes vestes adornado

Himeneu rompe o ar, e à Trácia voa,

Lá donde o chama Orfeu, porém debalde.

$\mathrm{O}$ deus sim presidiu do vate às núpcias,

5 Mas não levara ali solenes vozes,

Nem presságio feliz, nem ledo rosto.

Sentiu-se apenas crepitar-lhe o facho,

E em vez de viva luz soltar um fumo

Lutuoso, e fatal: vãmente o nume

10 Tentou co movimento erguer-lhe a chama.

$\mathrm{O}$ efeito foi pior que o mesto agouro.

Enquanto a linda noiva os prados gira,

Das náiades gentis acompanhada,

Áspide oculto fere o pé mimoso:

15 Morre a moça infeliz, e o triste amante

Depois de a lamentar aos Céus, e à terra,

Empreende comover do Inferno as sombras;

Afouto desce a vós, Tenárias portas.

Por entre baralhada, aérea turba

20 Cujos restos mortais sepulcro logram,

Aos negros paços vai do rei das trevas,

Vê do tirano eterno o trono horrendo.

Lá casa os sons da voz, e os sons da lira,

Às deidades cruéis lá diz: "Oh deuses,

25 Deuses do mundo sotoposto à Terra,

No qual se há-de sumir tudo o que existe!

Se acaso a bem levais que ingênuas vozes

$\mathrm{O}$ artifício removam, crede as minhas.

Não venho para ver o opaco Averno,

30 Nem para agrilhoar as três gargantas

Do monstro Meduseu, que erriçam cobras.

Atrai-me ao reino vosso a morta esposa,

A quem pisada víbora o veneno

Nas veias desparziu, a flor murchando

35 Dos anos festivais, inda crescentes.

Constância quis opor ao dano acerbo,

Tentei vencer meu mal, e Amor venceu-me.

Este deus é nos Céus bem conhecido,

Aqui não sei se o é, mas se não mente

40 No rapto que pregoa antiga fama,

Vós também pelo Amor ligados fostes.

\footnotetext{
${ }^{9}$ Segundo o texto da edição portuguesa de Lello \& Irmão (BOCAGE, 1968).
} 
Ah! Por este lugar, que abrange o medo, Por este ingente caos, silêncio vasto, Que do profundo império o seio ocupam,

45 De Eurídice gentil à doce vida

O fio renovai, tão cedo roto.

Ela, todo o mortal vos é devido,

Vem tudo, agora, ou logo, à mesma estância.

Por aqui pende tudo, é este o nosso

50 Derradeiro, infalível domicílio;

Vós tendes, vós gozais, a vós compete

Da espécie humana o senhorio imenso;

A que exijo de vós há-de ser vossa

Por inviolável jus, por lei dos Fados,

55 Tocando o termo da vital carreira:

O uso do meu prazer em dom vos peço.

Se o Destino repugna ao bem, que imploro,

Se a esposa me retém, sair não quero

Deste horror: exultai coa morte de ambos."

$60 \mathrm{O}$ triste, que assim une o verso à lira

Os exangues espíritos deploram:

À fugaz linfa Tântalo não corre:

A roda de Ixíon de assombro pára:

Os abutres cruéis não mordem Tício,

65 As Bélides os crivos cair deixam,

$\mathrm{Tu}$, Sísifo, te assentas sobre a pedra.

Das vencidas Eumênides é fama

Que pela vez primeira os negros olhos

Algumas tênues lágrimas verteram.

70 Nem a esposa feroz, nem Dite enorme

Ousam negar piedade ao vate orante,

Chamam súbito Eurídice. Envolvida

Entre as recentes sombras ela estava:

Eis o mordido pé vem manso, e manso.

75 Recebe o trácio Orfeu coa bela esposa

Lei de que para trás não volte os olhos

Enquanto for trilhando o feio abismo,

Se nula não quiser a graça extrema.

Por duro, esconso, desigual caminho,

80 De escuras, vastas névoas carregado,

Um após outro os dois, vão em silêncio:

Já do tartáreo fim distavam pouco.

Temendo o amante aqui perder-se a amada, Cobiçoso de a ver, lhe volve os olhos:

85 De repente lha roubam. Corre, estende

As mãos, quer abraçar, ser abraçado,

E o mísero somente o vento abraça.

Ela morre outra vez, mas não se queixa,

Não se queixa do esposo; e poderia

90 Senão de ser querida lamentar-se?

Diz-lhe o supremo adeus, já mal ouvido;

E recai a infeliz na sombra eterna.

Fica atônito Orfeu coa dupla morte

Da malfadada esposa, como aquele

95 Que num dos colos viu com rijos ferros

Preso, arrastado à luz o cão trifauce,

E que o mudo pavor despiu somente

Quando despiu a natureza humana,

Transformado em rochedo imoto, e frio;

100 Ou qual o que a si mesmo impôs um crime, 
Óleno, que de réu quis ter o nome

Por te salvar, misérrima Leteia,

Orgulhosa de mais com teus encantos,

$\mathrm{Tu}$, que foste co esposo outrora uma alma

105 Repartida em dois corpos, que hoje és pedra

Com ele, e juntos no Ida estais sustidos.

$\mathrm{O}$ estígio remador expulsa o vate,

Que ora, que em vão tornar ao Orco intenta.

Sete dias jazeu na margem triste

110 Sem nutrimento algum: só a saudade,

As lágrimas, a dor o alimentaram.

Depois de prantear vossa fereza,

Numes do Inferno, ao Ródope se acolhe,

E ao Hemo, de Aquilões sempre agitado.

115 Dera o giro anual três vezes Febo,

E sempre o terno Orfeu de amor fugia,

Ou porque o mal passado o refreava,

Ou porque eterna fé jurado houvesse

A miseranda esposa: repulsadas

120 Mil belas ninfas seus desdéns carpiram.

Os 82 hexâmetros de Ovídio foram traduzidos por Bocage em 120 decassílabos. A grande diferença numérica de versos causa, a princípio, a impressão de um certo transbordamento da frase em português. No entanto, ao observar o princípio da proporcionalidade métrica, baseada na extensão silábica absoluta dos versos em latim e em português, percebe-se a justeza do método intuitivo de Bocage: dividindo-se 120 por 82, chega-se a 1,46 (dec./hex.), resultado bastante próximo da razão ideal há pouco descrita.

A título de exercício de aplicação, apresenta-se a seguinte tradução ${ }^{10}$ para o mesmo trecho das Metamorfoses, na tentativa de verificar a possibilidade de reiteração prática da proporcionalidade métrica, de acordo com a mesma fórmula:

Vestido com seu manto de açafrão, de lá do éter imenso Himeneu desce ao litoral dos cícones, na Trácia, em vão chamado pela voz de Orfeu.

5 Ele esteve presente ao casamento, sim, mas não trouxe nem semblante alegre nem palavras solenes e felizes.

E a tocha mesma que ele segurava sibilou lacrimosa o tempo todo

10 sem que acendesse dançarina chama.

Mais grave a consequência que o auspício: enquanto vaga a noiva pela relva, do cortejo das Náiades seguida, cai morta pelos dentes de uma víbora

15 que no pé delicado se lhe encravam. Depois de lamentar-se muito aos céus, vem à porta tenária $\mathrm{e}$, decidido, desce o vate do Ródope ao Estige, a fim de comover até as sombras.

20 Por entre a tênue multidão de espectros, caminha até Perséfone e o senhor

\footnotetext{
${ }^{10}$ Feita pelo autor deste trabalho.
} 
que impera no inameno reino umbroso. Tocando a lira enquanto canta, diz:

"Ó deuses deste mundo subterrâneo,

25 no qual há-de cair todo mortal, se não levais a mal que assim vos fale sem falsos circunlóquios a verdade, não venho para ver o escuro Tártaro nem para acorrentar as três gargantas

30 do monstro meduseu, pelo de cobra. Minha esposa é o motivo da viagem: pisada víbora instilou-lhe o fel e arrebatou-lhe a vida à flor da idade. Quisera então vencer a dor mas, não,

35 venceu-me Amor, um deus bem conhecido nos reinos lá de cima, aqui não sei. Mas mesmo aqui suponho que o conheçam, pois, se a fama do antigo rapto é certa, a vós também outrora Amor uniu.

40 Por estes ermos plenos de temores, por este ingente Caos e pelo vasto silêncio deste reino, eu vos suplico: retecei o veloz fado de Eurídice! Tudo a vós se destina e, cedo ou tarde,

45 a um único lugar nos recolhemos: para cá sem demora todos vêm. Esta é a nossa morada derradeira, e sois portanto vós que possuís da humana raça o mais longo domínio.

50 Eurídice também, quando, madura, seus justos anos já tiver vivido, há-de ser por direito sempre vossa, e eu não vos peço mais do que preciso. Se à esposa tal favor negam-me os fados,

55 é certo que eu não queira mais voltar: ah, com a morte dos dois, regozijai-vos!" Assim ele dizia ao som da lira, e, embora exangues, almas soluçavam; d'água que foge Tântalo esqueceu-se,

60 parou sem mais a roda de Ixião, não devoraram vísceras as aves, as Bélides livraram-se dos jarros, e, Sísifo, sentaste em teu rochedo. Conta-se que, vencidas pelo canto,

65 em lágrimas banharam as Eumênides pela primeira vez as próprias faces. Nem a real consorte nem aquele que rege as profundezas são capazes de ao súplice negar: chamam Eurídice.

70 Estando ela entre as sombras novas, vem, por causa da ferida, a passo lento.

Orfeu recebe a esposa e junto a ordem de não voltar os olhos para trás enquanto não deixar do Averno os vales

75 - ou de nada o favor lhe serviria. Percorrem, em silêncio mudo, um íngreme, árduo e sombrio caminho que se estende em meio a denso e negro nevoeiro. E já da superfície se aproximam, 80 quando ele, receoso de perdê-la, 
volta os ávidos olhos de paixão

para trás: para trás ela se vai;

e, os braços estendendo e debatendo, ela quer segurar-se e nada agarra

85 a não ser, infeliz, o vento infrene.

Mas, morrendo de novo, não se queixa do esposo (pois de que se queixaria a não ser de ter sido tão amada?).

Disse um último adeus, que mal se ouviu,

90 e recaiu no abismo que deixara.

Ao ver morrer a esposa novamente, Orfeu ficou parado como aquele que viu, temendo, o cão de três cabeças com o pescoço do meio acorrentado,

95 a quem o espanto não deixou senão depois que a natureza o abandonasse, tendo em rochedo o corpo transformado; ou como o que acusou-se e quis a culpa, ó Óleno, sem tê-la, e tu, Leteia,

100 que, infeliz, confiaste em ser tão bela - dois corações outrora inseparáveis, agora pedras sobre o úmido Ida.

$\mathrm{O}$ barqueiro repele o que lhe pede para de novo o rio atravessar;

106 e, esquálido, na margem fica Orfeu por sete dias sem os dons de Ceres: tristeza imensa e dor profunda e lágrimas foram seu alimento na amargura.

Dos cruéis deuses do Érebo queixou-se,

110 recolhendo-se ao cimo do alto Ródope e ao Hemo frio que os aquilões fustigam. $\mathrm{O}$ terceiro Titã findara o ano que com os peixes do mar se encerra, e Orfeu fugia às femininas seduções,

115 ou por the ter o amor sido infeliz, ou porque um juramento houvesse feito. $\mathrm{E}$ as mulheres ardiam pelo vate; rejeitadas, porém, sofriam muito.

Dessa vez, os 82 hexâmetros de Ovídio foram vertidos em 118 decassílabos (apenas 2 a menos do que a tradução de Bocage). Extraindo-se a razão silábica, tem-se 1,43 dec./hex. (118 dec. : 82 hex.), resultado também bastante próximo da razão métrica ideal, que confirma a possibilidade de aplicação daquela fórmula de proporcionalidade na busca de uma equivalência estilística baseada na materialidade da expressão. Trata-se, sem dúvida, de um modelo que impõe à tradução um forte princípio de regularidade, evitando que a frase em português se torne frouxa ou tensa demais. Contudo, convém dizer, não se pretende com isso fixar regras para a tradução do hexâmetro datílico, senão apenas refletir um pouco sobre uma possibilidade que parece conformarse bem à índole do vernáculo. 


\section{Referências bibliográficas}

BAndeIRA, Manuel. Poesia e verso. In: . De poetas e de poesia. Ministério da Educação e Cultura (Serviço de documentação), [19--], p. 107-124.

Bocage, Manuel Maria Barbosa du. Obras de Bocage. Porto: Lello \& Irmão, 1968.

BRODSKY, Joseph. O filho da civilização. In: . Menos que um. Trad. S. Flaksman. São Paulo: Companhia da Letras, 1994, p. 73-87.

CAMÕES, Luís de. Os Lusíadas. In: . Obra completa. Rio de Janeiro: Nova Aguilar, 2003, p. 8-264.

Huizinga, Johan. Homo ludens: o jogo como elemento da cultura. $4^{\mathrm{a}}$ ed. Trad. João Paulo Monteiro. São Paulo: Perspectiva, 1996.

JAKOBSON, Roman. Linguística e comunicação. 22 $2^{\underline{a}}$ ed. Trad. Isidoro Blikstein e José Paulo Paes. São Paulo: Cultrix, 2001.

LOPES, Edward. Fundamentos da linguística contemporânea. São Paulo: Cultrix, 2005.

Ovide. Les métamorphoses. Texte établi et traduit par Georges Lafaye. Paris: Les Belles Lettres, 1985 (v.1), 1989 (v.2), 1991 (v.3).

OvíDIo. Metamorfoses. Trad. Manuel Maria Barbosa du Bocage (Intr. João Angelo Oliva Neto). São Paulo: Hedra, 2007.

PAz, Octavio. El arco y la lira. 3- ed. México: Fondo de Cultura Económica, 1990.

Romero, Sílvio. Folclore brasileiro: cantos populares do Brasil. Belo Horizonte, São Paulo: Itatiaia/EdUSP, 1985.

VALÉrY, Paul. Variedades. Trad. Maisa Martins de Siqueira. São Paulo: Iluminuras, 1999.

VIRGILE. Énéide. $8^{\mathrm{e}}$ ed. Texte établi par Henri Goelzer et traduit par André Bellessort. Paris: Les Belles Lettres, 1956. 